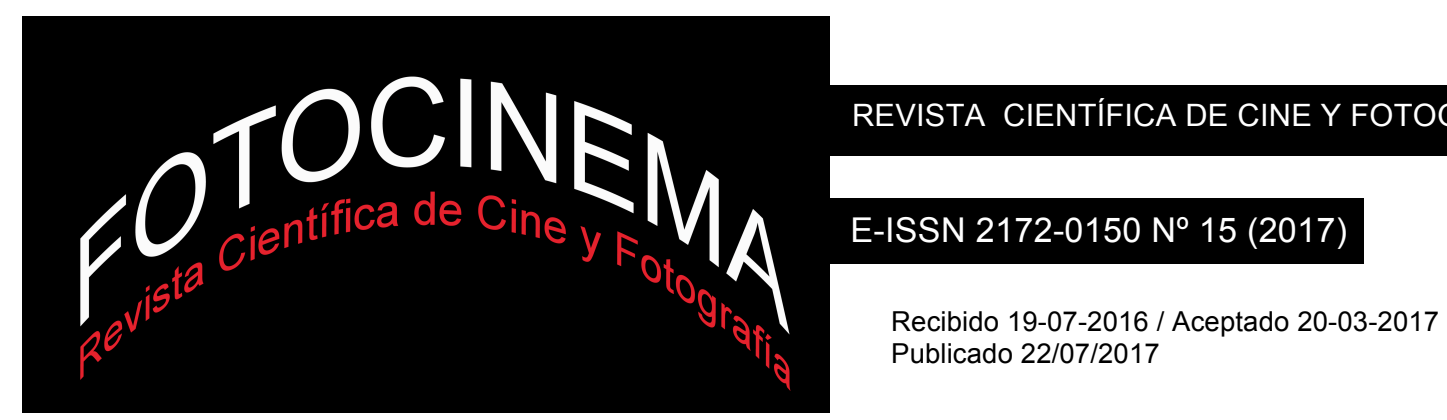

\title{
EL ORDEN DE LOS FACTORES... LAS REESCRITURAS DE TUTE CABRERO: ENTRE TELEVISIÓN, CINE Y TEATRO
}

\section{THE ORDEN OF THE FACTORS... THE REWRITING OF TUTE CABRERO: AMONG TELEVISION, CINEMA AND THEATER}

Jorge Sala

CONICET, Universidad de Buenos Aires, Argentina jorgesala82@hotmail.com

\section{Resumen:}

El film Tute cabrero (Juan José Jusid, 1968) constituye un caso extraño de traslación de un texto dramático a la pantalla dentro del panorama de las producciones cinematográficas argentinas de los sesenta. Escrito originalmente como un guión televisivo por Roberto Cossa (el dramaturgo teatral más importante del realismo de la década) la obra fue llevada primero al cine sin haber tenido previamente otra difusión. Años más tarde, en 1981, el propio Cossa reescribiría su propio material para estrenarlo en los escenarios. El trabajo analiza, desde una perspectiva semiopragmática, estos procesos de trasvase múltiple -del guión, al cine y finalmente al teatro- buscando recuperar no solo las transformaciones operadas en estos pasajes sino también las huellas persistentes y la incidencia que los diversos medios tuvieron en las distintas versiones

\begin{abstract}
:
The film Tute Cabrero (Juan José Jusid, 1968) is a strange case of translation of a dramatic text to the screen within the panorama of argentine cinematographic production of the sixties. Originally written as a television script by Roberto Cossa (the most important theatrical playwright of the realism of the decade) the work was first made into a film without having previously had other promotion. Years later, in 1981, Cossa will rewrite his own material to be released in stages. This work analyzes, from a semiopragmatical perspective, these processes of multiple transfer -from script to the cinema and finally to the theaterlooking for recover not only the transformations that operates in this passages but also the persistent traces and the incidence that the medias had in the different versions.
\end{abstract}

Palabras clave: reescritura; cine argentino; teatro; años sesenta.

Keywords: Rewrite; Argentine Cinema; Theater; Sixties. 
Cómo citar: Sala, J. (2017). "El orden de los factores... Las rescrituras de Tute cabrero. Entre televisión, teatro y cine". Fotocinema. Revista científica de cine y fotografía, $\mathrm{n}^{0}$ 15, pp. 229-260. Disponible: http://www.revistafotocinema.com/

\section{Introducción y metodología}

En Argentina los años sesenta fueron una etapa en la cual se vislumbró una andanada renovadora en las prácticas culturales dentro de un proceso acelerado y espasmódico. La crisis del modelo clásico-industrial en el cine, avivada tras el derrocamiento del segundo gobierno de Juan Domingo Perón (1955) estuvo acompañada por la emergencia, al igual que lo sucedido en otras cinematografías, de un movimiento modernizador inclinado a disputar un espacio de reconocimiento. De este modo, las innovaciones gestadas en paralelo en la literatura, el teatro y las artes visuales tendieron a entablar puentes e intercambios a través de un diálogo fecundo que el cine no tardaría en recuperar. En un marco como aquél, el "ser moderno", además de un imperativo, pasó a convertirse en una marca de reconocimiento (sobre todo entre los jóvenes creadores) que permitió trazar un punto de quiebre respecto al pasado inmediato al mismo tiempo que coadyuvaba a fundar una casi obligada asociación entre pares.

Particularmente en lo que refiere a las relaciones entre el teatro y el cine gestadas al amparo de dichas transformaciones, estas disciplinas construyeron una historia particular pautada por distintos momentos de intensidad. Mientras en los primeros años de la década se asiste a lo que denomino como fase de legitimación horizontal en la que los agentes de ambos campos desarrollaron contactos con vistas a su propia inserción al interior de sus respectivos espacios diferenciales, en la segunda mitad de los sesenta se detecta el pasaje a una fase de intermedialidad profunda, basada en la progresiva difuminación de los límites entre las prácticas artísticas, lo cual redundó en una mutación tanto de sus estrategias de vinculación como de los productos derivados de sus conexiones. Dentro de esta división, la reescritura ${ }^{1}$ de obras teatrales por el cine

\footnotetext{
${ }^{1}$ Utilizo el término reescritura en lugar de los más difundidos "adaptación” y "transposición” debido a su
} 
- una de las formas posibles de manifestación de estos cruces, aunque no la única- experimentó un conjunto de modificaciones: mientras en la primera etapa era moneda corriente que un cineasta (o aspirante a convertirse en uno) retomara una pieza ya estrenada -aunque no demasiado difundida- de algún elenco independiente, durante la fase de intermedialidad profunda esta asociación interdisciplinar asumió nuevas variantes. Este es el caso del film que estudiaré a continuación. La ópera prima de Juan José Jusid, Tute cabrero (1968), constituye un ejemplo extraño de traslación de un texto dramático a la pantalla dentro de la tradición cinematográfica local basada en obras previas. Escrito originalmente como un guión televisivo por Roberto Cossa (una figura clave dentro de la renovación dramatúrgica de la década) la historia de los oficinistas que deben decidir por ellos mismos cuál de los tres deberá ser despedido fue llevada primero al cine sin haber tenido previamente otra difusión. Años más tarde, en 1981, el propio Cossa reescribiría su propio material para estrenarlo en una sala teatral. ¿Qué tenemos, entonces? Un caso anómalo para la época en el que un texto, concebido por un teatrista para un medio (el televisivo) se transforma en película y finalmente efectúa el trayecto inverso (o casi) hasta terminar montado en un escenario. Me interesa detenerme específicamente en ese itinerario de ida y vuelta. El propósito de este trabajo es analizar los modos en que se efectuaron los pasajes alrededor del texto estudiando no solamente los cambios desplegados entre las distintas versiones (tomando como ejes el guión publicado, la puesta en escena fílmica, el texto dramático y los registros y referencias visuales sobre el espectáculo teatral) sino también poniendo el acento en las huellas persistentes de las disciplinas en cuestión sobre las restantes. Como un verdadero palimpsesto recobrando el título del célebre libro de Gerard Genette (1989)- cada versión puso de manifiesto los rastros, los signos identitarios, de los medios precedentes.

Debido al interés por encuadrar el fenómeno en su complejidad, el análisis comparativo de tipo semiótico deberá complementarse con una mirada atenta a

capacidad de condensar algunos problemas propios de la época en cuestión. Según José Antonio Pérez Bowie, adoptar este término resulta productivo sobre todo al colocar el foco analíticamente alrededor de películas como las producidas dentro del cine moderno, las cuales "representan un mayor interés por albergar una opción personal mediante la que el realizador lleva a cabo una auténtica reelaboración del texto de partida proyectado sobre él sus propios intereses ideológicos y estéticos además de las determinaciones derivadas del nuevo contexto en el que se inscribe su creación” (2010: 26). 
interrogarse sobre las condiciones de producción de los discursos. Por lo tanto, el enfoque privilegiará el estudio del contexto en el cual estos se llevaron a cabo, al igual que una mirada sobre otros aspectos no deducibles directamente de los propios textos (teatrales - ya sean dramáticos o espectaculares-o fílmicos). En este sentido, la perspectiva teorizada por Patrick Cattrysse (1992) sobre la necesidad de analizar tanto los procesos como los productos permitirá, a la vez que ampliar el campo de visión, incorporar al examen algunas experiencias contemporáneas provenientes de las artes visuales que servirán para determinar otras instancias de cruce posibles más allá de aquellas suscitadas por las vinculaciones entre un texto fuente y un texto destino.

Previo al análisis de los sucesivos trasvases de Tute cabrero y de las relaciones intermediales entre teatro, cine y televisión se procederá a efectuar una sucinta caracterización de las dos etapas históricas por las que atraviesa la relación cinematográfica y teatral en la Argentina de los sesenta: aquella enmarcada dentro de la "legitimación horizontal" con relación a una segunda, de “intermedialidad profunda”. A partir del trazado de sus rasgos principales se logrará situar a esta obra dentro del contexto de producción modernizador de la década. Una vez delineados los términos históricos, el artículo dará cuenta brevemente de la trayectoria de sus artífices (Juan José Jusid y Roberto Cossa) buscando determinar los puntos de contacto que tornaron factible el encuentro entre sus perspectivas estéticos-ideológicas y la labor mancomunada emprendida que dio como resultado el film. Entendido como un espaldarazo recíproco, el contacto entre un dramaturgo emergente y un cineasta operaperimista funcionó como una estrategia de reconocimiento mutuo que fortaleció ambas carreras. A través de este doble marco (epocal y de los agentes intervinientes) se podrán recortar mejor las especificidades de las traslaciones del guión televisivo al cine y de allí a la puesta en escena teatral en términos inmanentes.

\section{Las dos etapas de las relaciones entre el cine y el teatro argentino de la modernidad}

La larga década del sesenta (Jameson, 1984), aquella situada para el caso argentino entre dos golpes de estado (1955 y 1976) aparece como un período 
clave de reconfiguración tanto de las prácticas artísticas como de las interrelaciones que estas llevaron a cabo. Debido a la necesidad de establecer una demarcación interna se detectaron dos fases sucesivas. La primera de ellas, situada entre 1956 y 1964, se define por la aparición de un conjunto de artistas, jóvenes en su gran mayoría, que empiezan a mostrar sus primeras creaciones y a disputar un lugar de reconocimiento al interior del campo artístico local. Como un signo específico, estos promovieron unas alianzas coyunturales entre diversas disciplinas como mecanismo que les permitió integrarse dentro de sus propios espacios específicos. Se trató, como señala Oscar Terán en su análisis de los intelectuales de la época, de "un movimiento de consagración horizontal típico de momentos de crisis de hegemonía del campo intelectual, y por el cual quienes ingresan al mismo rehúsan el reconocimiento desde la cúspide de los ya distinguidos y apelan por ende a autoconsagrarse entre sí” (Terán, 1991, p. 19). En lo que refiere a las relaciones cinematográficas y teatrales, dentro de esta fase de legitimación horizontal los artistas emergentes compartieron espacios (los teatros independientes, los cineclubes, las revistas especializadas) y tendieron lazos con vistas a la obtención de capital simbólico. Frente al cine clásico de los años cuarenta y cincuenta, en el cual sus principales artífices se caracterizaron por emplear mayormente textos canónicos del teatro y la literatura nacional y universal, en esta fase los nuevos cineastas optaron por apelar a obras con un grado menor de legitimidad, cuestión que determinó la horizontalidad referida al presuponer que se trataba de una alianza de pares y no de un vínculo entre prácticas "mayores" y "menores". Tres de las primeras reescrituras cinematográficas de obras teatrales del período $-E l$ crack (José Martínez Suárez, 1960), Los de la mesa 10 (Simón Feldman, 1960) y El centroforward murió al amanecer (René Mugica, 1961) - corresponden a esta lógica en la que unos directores desconocidos se valieron de unas obras de circuitos independientes que contaban con una circulación restringida y minoritaria. Por otra parte, la fase de legitimación horizontal implicó un importante quiebre artístico en función del surgimiento de una cantidad considerable de nuevos nombres dispuesta a mostrar sus creaciones. En función del valor otorgado a la novedad, los artistas emergentes y las alianzas establecidas dotaron a los sesenta argentinos de su particular ethos modernizador. 
El año 1965 marca el inicio de otro momento singular dentro de este trayecto histórico. El mismo se extiende hasta 1973, con algunos puntos clave en su interior. Esta segunda fase, caracterizada como de intermedialidad profunda, representa una instancia en la que los intercambios artísticos se intensificaron cualitativamente al punto que gran parte de las producciones y los proyectos artísticos aparecen como parte de un gran magma común. Una de las claves principales del rumbo que asume la modernidad radica en la mayor complejidad al momento de diferenciar la pertenencia de una creación a una disciplina específica. La consolidación del happening en el circuito artístico porteño representa un síntoma de esta difuminación de las esferas. Según lo concibiera Oscar Masotta, este "es un género de actividad artística que comienza por ampliar la extensión misma de la noción de obra" (2004 [1967], p. 202), postulando más adelante que "como tiende a neutralizar esas oposiciones y a homogeneizar hombres y cosas, el happening comienza por hacer más improbable, más difícil la noción misma de 'materia': como arte, es desde entonces una actividad a la cual es difícil fijar su 'lugar' social” (Masotta, 2004 [1967], p. 293).

La puesta en funcionamiento en 1965 del Centro de Experimentación Audiovisual del Instituto Di Tella (CEA, que en su misma nomenclatura propicia esta idea de mezcla bajo el paraguas común de lo "audiovisual”) es el resultado de la enorme permeabilidad expresada por cada una de las artes. Un movimiento de hibridación que alcanzaría en esos años tal grado de expansión que terminaría por volver parte de su entramado discursivo lo indiscernible como categoría. Longoni y Mestman definen como una característica de esta época que "las pertenencias 'disciplinarias' no eran estancas: en muchos casos, los roles eran múltiples, intercambiables, los lugares no estaban delimitados (...) se exceden los límites tradicionales de los géneros, al mezclarlos, y también los lugares asignados a cada actividad" (2008 [2001], p. 74). Bajo este panorama se explayan con libertad algunos de los productos más granados de esta expansión de las esferas que terminaría inclinándose hacia la indeterminabilidad. Los happenings - La menesunda (Marta Minujín y Rubén Santantonín, 1965), Simultaneidad en simultaneidad (Minujín, 1966)- o ciertos filmes emparentados a esta atmósfera - The Players versus Ángeles Caídos (Alberto Fischerman, 1969), Tiro de gracia (Ricardo Becher, 1969)- podían ser 
pensados como verdaderos textos de cruce, tanto por sus estrategias de producción como por las formas en que circularon y fueron recibidos por el público. En las creaciones de avanzada ya no era posible reconocer la marca de origen de sus procedimientos constitutivos o la asignación de raíces a sus artífices o participantes. En un sentido más profundo, estas prácticas fueron la consecuencia esperable de una tendencia que militaba activamente alrededor de una visión afirmativa del modernismo. Según Marshall Berman, para quienes defendieron en la segunda mitad del siglo XX las ventajas de la modernidad, cobró protagonismo "romper con las barreras existentes entre el 'arte' y otras actividades humanas como el entretenimiento y la tecnología industrial, la moda y el diseño, la política" (2005 [1985], p. 99).

Tute cabrero se estrenó en 1968, configurándose como un ejemplo acabado de la difuminación de la esferas artísticas que dominó en esta fase. Aun cuando la mixturación y la inespecificidad disciplinar característica de esta fase no afecta su organización formal, sí movilizan rasgos innovadores en lo relativo a su origen y al modo en que se encaró su trasvase. En un horizonte en el que las zonas dejaron de estar delimitadas claramente pudo aparecer una película como la ópera prima de Jusid, basada en una pieza inédita escrita por un dramaturgo surgido a principios de los sesenta no para los escenarios sino para la televisión y que, no obstante, tuvo primero su paso por la gran pantalla antes que por el teatro o por otro medio. Si en el pasado un orden probado en la práctica indicaba que las reescrituras fílmicas se gestaban con posterioridad al estreno de las piezas en salas teatrales (contando con un mayor o menor conocimiento por parte de los potenciales espectadores), con esta película se invierte la relación y el cine ocupa el primer lugar dentro de este trayecto de ida y vuelta que emprende la pieza de Cossa.

\section{El espaldarazo recíproco}

La cercanía de Juan José Jusid con el teatro se inició, según declaró él mismo, a una edad muy temprana, con bastante anterioridad al inicio de su trayectoria en el campo del cine. Este vínculo signó las primeras décadas de trabajo como realizador, cumpliendo un papel determinante en su decisión de llevar a la pantalla Tute Cabrero en lo que fue su primera incursión en la dirección de un 
largometraje. Su padre fue uno de los fundadores del teatro IFT; a los quince años Jusid se unió al elenco independiente Fray Mocho donde desarrolló actividades como titiritero. Más adelante, formado profesionalmente dentro del film publicitario, la impronta teatral permaneció latente y tuvo ocasión de manifestarse con insistencia sobre todo a partir del vínculo que trabó con diversos autores locales. Casi como una marca autoral distintiva, su filmografía apeló al universo de los dramaturgos pertenecientes al realismo toda vez que su cine tendió a afianzarse en el costumbrismo, en la fuerza de los diálogos y las actuaciones y en la preponderancia de la tesis por encima de la artificiosidad o del despliegue espectacular. ${ }^{2}$ Sin embargo, pese a la significativa constancia de la intervención de los teatristas en su obra, desde el comienzo Jusid identificó el cine que le interesaba producir más en consonancia con la narrativa que asociado a experiencias escénicas específicas. Ya en un temprano texto que acompañó la publicación del guión de Tute cabrero, el cineasta defendía su inclinación en estos términos: "Filmar era para mí algo así como relatar una ficción. Narrar. Y precisamente me desilusionaba en nuestro cine la carencia de auténticos narradores" (Weiss \& Jusid, 1968, p. 80). Aquello que generaba cierto encono en el aspirante a realizador tenía que ver con el vacío predominante en las acciones propia del cine moderno local de la primera parte de los sesenta y que había alcanzado en los trabajos de Rodolfo Kuhn - Los jóvenes viejos (1962) - y David Kohon -Tres veces Ana (1961) - sus puntos más altos. Frente a estas propuestas, emparentadas con la noia del universo de Antonioni o de algunos filmes de la Nouvelle vague, Jusid abogaba por un cine que recuperara el carácter fundante de las acciones y basado en la solidez narrativa. En función de esta premisa cobró fuerza la figura de Roberto Arlt, escritor y autor teatral de los años veinte y treinta que por esos años había recobrado un inusitado prestigio entre los intelectuales (Jordan, 2007). El cineasta comentó en una entrevista algunos datos sobre los prolegómenos de la

\footnotetext{
2 Además de este trabajo inicial junto a Cossa, en su filmografía posterior aparecen otros nombres pertenecientes a estas tendencias de la dramaturgia nacional: con Roberto Perinelli desarrolló la escritura de La fidelidad (1970); Jorge Goldenberg y Oscar Viale colaboraron en la transcripción de los cuentos de Alberto Guerchunoff para Los gauchos judios (1975) y posteriormente en No toquen a la nena (1976); Carlos Somigliana firmó el guión de Asesinato en el senado de la nación (1984); finalmente, esta etapa se cierra con la traslación de una pieza teatral de enorme repercusión pública como fue Made in Lanús (1986), de Nelly Fernández Tiscornia, convertida en su pasaje a la pantalla en Made in Argentina (1987).
} 
filmación de Tute cabrero y el modo en que se interceptaron las textualidades de Cossa y Arlt:

Yo tengo una relación con Tito Cossa que empieza cuando asistí a una de las primeras funciones de Nuestro fin de semana, la obra que a él lo posicionó. Yo tenía la idea de hacer una historia de oficina para enganchar con otras dos que iban a hacer otros realizadores, Pablo Szir y Jorge Cedrón (...) Yo andaba con ganas de adaptar La isla desierta, una obra corta de Roberto Arlt (...) Cuando se lo conté a Tito y le pedí ayuda me dijo: “Mirá, ¿̇por qué no lees algo que escribí para un concurso del Fondo de las Artes que ganó el premio pero nunca se realizó, ni se editó?” Era Tute Cabrero, pensado como un guión para televisión (En Peña, 2003, p. 131. Subrayado en el original).

La imposibilidad de llegar a un acuerdo económico sobre los derechos de la pieza de Arlt -tomando en consideración el hecho que se trataba de un realizador sin experiencia previa- provocó que Jusid aceptara la oferta de Cossa y utilizara su texto como punto de partida. En el fondo, el tema y el ambiente planteados en Tute cabrero guardaban una conexión con el clima de encierro oficinesco que imperaba en aquel drama estrenado en 1937. Por otro lado, el plus aportado por este cambio poseía otras aristas seductoras: a la actualidad de la problemática abordada por el relato se sumaba su referencialidad concreta, distante del estilo expresionista de La isla desierta. Todavía más importante que las cuestiones anteriores, también aparece como un dato a tener en cuenta el hecho no menor de que el ofrecimiento implicaba la posibilidad de tener a su disposición una obra galardonada y aún así desconocida por el público.

Si bien los primeros textos de Cossa, Nuestro fin de semana (1964), Los días de Julián Bisbal (1965) y La pata de la sota (1967) gozaron de una difusión creciente en teatro y televisión, no tuvieron hasta Tute cabrero una inserción en el cine. Por ende, el encuentro del dramaturgo con Jusid significó un espaldarazo recíproco: una acción que colocaba, por primera vez dentro del campo cinematográfico la producción de un autor joven y aparejado a esto el surgimiento público de un cineasta apoyado en la textualidad de una figura en ascenso pero todavía a ser descubierta por amplios sectores de la platea. Parecía repetirse entonces, una práctica común dentro de la fase de legitimación horizontal de principios de la década, con la diferencia de que en este caso, ya 
situados en una instancia diferente, la obra teatral permaneció oculta en beneficio de la aparición en primer lugar del film, rompiendo la lógica de obra fuente y obra destino que había predominado hasta el momento.

Frente al cine argentino contemporáneo cuestionado por el aspirante a realizador, la unión con Roberto Cossa brindaba la ocasión de trascender lo que consideraba un mal endémico dentro de las realizaciones de los sesenta: "la total chatura de los diálogos y lo convencional de las situaciones que atravesaban los personajes" (Weiss \& Jusid, 1968, p. 81). En este sentido, Jusid concebía al creador de Nuestro fin de semana como una solución a este escollo debido a que, según su criterio, se trataba de un "autor teatral en quien admiraba profundamente su talento para manejar estos elementos, la funcionalidad de las situaciones, la fluidez de los diálogos y la sorprendente habilidad en la pintura de sus personajes" (81). Además, con respecto al realismo que Cossa venía desarrollando en sus textos previos - no muy distante, por cierto, del cine argentino "abúlico" denostado por Jusid- Tute cabrero, debido a su raíz televisiva, poseía como elemento singular una cuota de tensión que al director le resultó atractiva para explorar narrativamente. El suspense, activado a partir de las expectativas puestas alrededor del desenlace en el que se determina la situación de los tres dibujantes, funcionó como un acicate que movilizó el interés para su traslado al cine.

\section{La reescritura inicial: del guión televisivo al largometraje}

Una de las primeras vicisitudes que el cineasta y el dramaturgo tuvieron que sortear durante el proceso de reescritura estuvo ligada al metraje originalmente pensado dentro de las acciones desplegadas en el texto. El guión de Cossa, organizado según un formato televisivo de una hora con intervalos, permitía rodar un film de aproximadamente 45 minutos. En principio esta duración se ajustaba al proyecto inicial de una película en episodios pero, al caerse la participación de Cedrón y Szir, los otros integrantes del tríptico, esto apareció como un problema mayor. Tute cabrero se encontró en una disyuntiva: su extensión no se ajustaba a la medida estándar de un largo y, por otra parte, superaba ampliamente la longitud habitual que la habilitaba a ingresar en la categoría de cortometraje. La necesidad de optar por uno de los dos caminos 
hizo que Jusid se propusiera el agregado de algunas escenas ilustrativas destinadas a situar las coordenadas topográficas de las acciones sin interferir demasiado en la lógica propuesta para la historia. Este "aireado" obligado de la versión inicial hizo que el relato se extendiera hasta alcanzar 65 minutos, prácticamente el mínimo necesario para ser considerado un largometraje y poder así competir dentro de los premios otorgados por el Instituto Nacional de Cinematografía (INC). Mediante la inclusión de imágenes de la ciudad y de una serie de planos de los personajes deambulando por distintas locaciones (el centro de Buenos Aires, la Costanera Sur) se lograba este cometido. Las traslaciones por la ciudad, además, anexaban otra ventaja: anclar referencialmente el drama oficinesco en un contexto cercano al del espectador. Con esto se alcanzaba el tono específico del film, el cual apuntaba a obtener la empatía afectiva de los potenciales receptores.

Entre las estrategias implementadas para ampliar la duración de las escenas volviéndolas fácilmente identificables aparece el uso de la cámara oculta. Si bien el recurso no resultaba novedoso para el cine de la época3 ${ }^{3}$ su incorporación provoca una integración de registros en apariencia dispares (ficción y documental) que redunda en el carácter realista del relato. La decisión de anexar escenas filmadas con unas cámaras escondidas capaces de captar situaciones en la que los actores interactuaban en la calle sin sostener una clara diferenciación con otras personas que transitaban por estos lugares estaba ya presente en el guión original:

\section{CALLE CÉNTRICA. DÍA NUBLADO}

Primeros planos de rostros de gente caminando por la calle, tomados de gran distancia con teleobjetivos.

Travelling sobre rostros desde coche. Se destaca su aislamiento.

Sosa en el coche de Carlos (Fiat 60o) mira por la ventanilla. Luego vuelve el rostro a Carlos.

SOSA: Oime Parenti... Hay algo que está muy claro. O el pibe o yo (...).

CARLOS: Vamos, terminala... (...).

\footnotetext{
${ }^{3}$ En El crack, José Martínez Suárez filma una extensa secuencia de un partido de futbol utilizando cámaras ocultas. Este procedimiento posibilitaba amalgamar la presencia de los actores al interior de un estadio repleto de espectadores asistentes a un encuentro deportivo sin que la presencia de los aparatos técnicos interfirieran en el comportamiento de unos extras involuntarios captados por el dispositivo.
} 
La cámara toma a los dos desde afuera del auto. Por el parabrisas desfilan infinitos reflejos. Atrás un poco grises se ven los rostros. (99)

En el film de Jusid, la incorporación de este registro configura una huella en la que se hace presente una relación clara con el directo televisivo, un procedimiento de transmisión propio de este ámbito y que en ese momento constituía una de las principales fuentes de diferenciación entre la televisión y lo cinematográfico (Carlón, 2006). Al configurar un diálogo entre estos medios, lo teatral queda subsumido y tiende a oscurecerse su presencia. Refiriéndose a los procedimientos que distinguen al cine del teatro, François Jost propone que una de las diferencias esenciales está fundada en lo que llama presunción de intencionalidad. Mientras en los escenarios prácticamente todo lo que aparece a la vista del espectador ha sido puesto de manera deliberada, en el cine hay una mayor posibilidad de integración de detalles sonoros o visuales que no fueron colocados ex profeso en la pantalla (en Pérez Bowie, 2004: 291). En Tute cabrero, la cámara, con su poder de captación de imágenes aleatorias, registra el paseo de los transeúntes anónimos mezclándolos con un movimiento en apariencia banal como es el deambular de los actores (Pepe Soriano y Juan Carlos Gené) por el espacio. Lo intencional de los intérpretes encarnando sus papeles se fusiona con lo accidental de las personas capturadas por un dispositivo invisibilizado. Del magma que produce la interacción entre la realidad y la ficción emerge un sentido atento a inscribir las acciones de los personajes dentro de un único sintagma que las equipara.

Además del mencionado parentesco con el directo, otra cercanía con la televisión está asociada al universo de referencias que Jusid tuvo en mente al momento de construir su film. En sus palabras, una fuente de inspiración, además de Arlt, fue 12 hombres sin piedad (12 Angry Men, Sidney Lumet, 1957), basada, al igual que Tute cabrero, en un guión para televisión -más tarde convertido en pieza teatral4- escrito por Reginald Rose. Según sus declaraciones, Jusid tomó como referencia esta película al intentar "imprimirle a la historia un ritmo nervioso, obsesivo, que agrede de lleno al espectador y lo obliga a definirse y tomar partido frente a lo que ocurre en la pantalla" (Tute

\footnotetext{
${ }^{4}$ En Buenos Aires, la versión escénica de Doce hombres en pugna -título con el que se conoció el film en Argentina- fue presentada en 1962 el Teatro Municipal General San Martín bajo la dirección de Carlos Muñoz.
} 
cabrero. iAl diablo con los esquemas!, p. 54). Teniendo en su horizonte un relato en el que los personajes del título dirimen encerrados en un único espacio clausurado la culpabilidad o inocencia de un presunto asesino, Jusid apuntó a conservar exclusivamente la atmósfera más que la lógica del encierro que impregna la trama de aquel film. Tendiendo a desteatralizar el guión de Cossa menguando, a su vez, todo lo que en él pervivía de guión televisivo destinado mayormente a unos sets-, el director articuló su puesta en escena buscando hacer visibles los instantes de mayor intensidad dramática en espacios abiertos (las calles o el paseo de la costanera) o públicos (un baño). La oficina, ese lugar hermético y de encuentro obligado para los protagonistas queda trazado en la banda de imágenes como un ámbito en el que predomina el silencio. Una vez instalado el conflicto central de la película, impera allí la incomunicación entre los otrora compañeros devenidos contrincantes en la lucha por conservar el empleo.

Si el encuentro personal -la instancia en la que dos o más personajes desnudan verbalmente sus verdades- constituye el principio constructivo de la dramática realista de los sesenta de la cual Tito Cossa se recorta como su mayor exponente, Jusid integra la aparición de dicho recurso en una puesta que rehúye de lo asfixiante que involucra paralizar a los sujetos obligándolos a desenmascararse “a puertas cerradas" (según rezaba el título de la libérrima pieza de Jean-Paul Sartre). La discusión callejera entre Sosa y Parenti aludida anteriormente o el reproche de Gladys (Cristina Moix) a Sergio Bruni (Luis Brandoni) sobre su delación al gerente con la Fuente de las Nereidas de fondo, tienen en común una determinación narrativa similar: los conflictos privados alcanzan toda su magnitud, contrariamente a lo que propone el teatro realizado en salas tradicionales, al explayarse en el espacio abierto y de tránsito. Bajo esta premisa, la película logra distanciarse al mismo tiempo de los escenarios y de los sets televisivos para el cual fue pensada originalmente.

El momento de mayor tensión del relato, aquel que expone la crisis entre Sosa y Bruni frente a los mingitorios de la empresa, sucede en un ambiente que aúna lo íntimo con lo público. La descripción espacial planteada en el guión es elocuente en su manera de postular, previo al desarrollo de las acciones, el entrecruzamiento entre lo abierto y lo privado: 


\section{BAÑOS DE ALFA. DÍA}

El baño de hombres tiene mucho movimiento.

Entra Sergio y dando la espalda se acomoda en un mingitorio. A su lado se desocupa otro. Lo ocupa Sosa. Las paredes tienen varias inscripciones. Se destaca una que dice: Barcel puto. ${ }^{5}$

Se ve el rostro de Sosa que mira en todas direcciones como buscando intimidad. Por fin su nuca se inclina hacia Sergio y le habla (115).

En este marco, pautado por una de las operaciones más íntimas del cuerpo pero también por la posibilidad de circulación de extraños y su posible interacción, se entabla el diálogo entre los compañeros de trabajo. La escena busca exponer la instancia en la que se produce el sinceramiento entre ambos personajes estableciendo un juego entre la situación privada y el lugar en el que esta se sitúa:

SOSA: Oíme pibe... Disculpame que te tutee... Yo en el único lugar que puedo trabajar es aquí. Si me echan, ¿dónde voy?...

Sergio termina de arreglarse el pelo frente al espejo. Observa que la gente abandona lentamente el baño hasta quedar vacío.

SERGIO: en esa situación estamos todos. Nos jugamos por igual.

Sosa levanta la voz.

SOSA: No, querido. No nos jugamos por igual. Si a mí me echan estoy listo. Pará... escuchame. Yo con cuatro años puedo largar todo.

Sergio quiere calmarlo.

SERGIO: Un momento.

Sosa en el máximo de la excitación lo toma de la solapa y le acerca el rostro a su cara. Sus ojos miopes, muy pequeños tras las gruesas gafas, parecen enrojecidos.

SOSA: iDejame hablar!... Vos sabés lo que es eso. Preciso seguir trabajando cuatro años, nada más... iY tiene que ser aquí!

Su voz retumba en las paredes del baño.

\footnotetext{
${ }^{5}$ Barcel es el apellido del gerente de Alfa. Es quien pone en aviso a los tres empleados de la determinación de despedir a uno de ellos y el que les enuncia que la decisión correrá por cuenta de ellos mismos.
} 
No te das cuenta?...

Lo suelta. Sergio se ordena la ropa y echa a andar. Atrás, como si recitara algo aprendido de memoria, Sosa lo sigue.

...Vos tenés veinticinco años... Tenés la vida por delante... (116-117).

Prácticamente en paralelo al estreno comercial de Tute Cabrero, el artista plástico Roberto Plate presentaba, en el marco de las Experiencias 68 auspiciadas por el Instituto Di Tella, su intervención conocida como "El baño". El dispositivo constaba de unos cubículos precedidos por unas puertas señalizadas con las inscripciones de "hombre” y "mujer" típicas de los sanitarios públicos. Los espectadores podían acceder al interior de estos espacios vacíos, carentes de los artefactos esperables. No obstante, las paredes guardaban la misma lógica que aquellos. Al igual que la frase "Barcel puto" que preside la discusión entre Sosa y Bruni, en el montaje de Plate los asistentes de la muestra del Di Tella se sintieron en libertad de dejar asentados en las paredes de la obra un conjunto de graffittis, tal como sucedería en cualquier baño de estación o bar. Lejos de ser accidental, la participación de la gente que circuló por la muestra estaba prevista (y deseada) dentro de la propuesta. A partir de esta construcción, "el autor buscaba que el público percibiera un resguardo de su intimidad suficiente como para producir 'actos de descarga a nivel emocional"” (Longoni \& Mestman, 2008, p. 113). Algunos de estos, dirigidos contra el gobierno militar en manos del General Juan Carlos Onganía, hicieron que un oficial de justicia y la policía decidieran clausurar la obra y prohibir a la gente su ingreso. 6

Lo valioso de la experiencia de Plate, siguiendo los señalamientos de María Fernanda Pinta, radica en su capacidad de reproducir, no un baño real, sino "su funcionamiento a la vez público y privado que permite la difusión de la denuncia y la preservación de la identidad anónima” (Pinta, 2013, p. 154).

Con pocos meses de diferencia, la propuesta de Roberto Plate y el film de Jusid encuentran unos puntos de conexión en el modo en que en ambos se construye la condición bifronte, entre pública y privada, entre íntima y social, de las

\footnotetext{
${ }^{6}$ Para un análisis exhaustivo del itinerario y los acontecimientos polémicos que acompañaron a las Experiencias 68, puede consultarse Longoni \& Mestman, 2008, pp. 100-120. La inserción de El baño de Roberto Plate dentro de la escena del arte conceptual de finales de los sesenta ha sido estudiada, entre otros, por Jaime Vindel, 2014, pp 529-531.
} 
situaciones allí enmarcadas. En la medida en que el baño de Alfa subraya la intersección entre lo personal y lo colectivo, los encuentros personales o, en otras palabras, esa suerte de actos de descarga a nivel emocional que estas acciones llevan consigo cobran una significación que se complementa con el lugar en el que se despliegan.

\section{Entre el guión, el film y el texto dramático}

Paradójicamente, pese a que la obra teatral no fue estrenada en esta etapa, el guión de Tute cabrero fue publicado (algo en lo que probablemente influyó la trayectoria de su autor). Igual suerte corrió el texto dramático del montaje teatral estrenado por el grupo dirigido por Raúl Serrano en 1981 (Cossa, 1997). Estudiar los cambios operados entre el primero y la puesta en escena fílmica, así como observar las diferencias existentes entre ambos textos conjuntamente a los datos suministrados por los registros del espectáculo torna factible el desarrollo de un interesante estudio comparativo. Una indagación atenta a revisar, por un lado, el grado de autonomía del proyecto creador de Juan José Jusid respecto de los planteos iniciales del guión y, en segundo lugar, la ocasión de encontrar posibles continuidades y alejamientos a partir del análisis de dos textos pensados para ser montados en disciplinas distintas. A su vez, la revisión de determinados elementos significativos de la puesta en escena cinematográfica a la luz de su correspondiente puesta teatral presentada por primera vez trece años después de la película demanda la necesidad de observar qué rasgos de la primera subsisten en la segunda, determinando así las influencias inversas del cine sobre el teatro.

El guión, la película de Jusid y la versión teatral establecen grados de separación ya desde las formas en que inscriben sus comienzos. Las modalidades de apertura que asumen sus respectivos relatos proponen un abanico de maneras expresivas que inciden en la percepción de sus totalidades. Presentando a los personajes, construyendo la prehistoria del conflicto o anticipándolo, configurando los puntos de vista y, en cierta sentido, el tono específico con el que serán expuestos los temas, las variantes en los inicios de estas tres obras, más que dejar percibir unos aires de familia típicos en cualquier proceso de 
reescritura, subrayan por el contrario la autonomía de cada discurso respecto de los anteriores.

El texto original publicado en 1968 proponía como inicio una escena en la que se mostraba a los personajes en un brindis de fin de año en la casa de Sergio Bruni. Se trata de una situación distendida cuya razón de ser estaba basada en la presentación de los protagonistas (y a sus parejas). Simultáneamente, su ubicación buscaba trazar brevemente un esbozo de la prehistoria en los que prevalecía la camaradería y un moderado afecto. Colocado a la manera de un prólogo previo al conflicto dramático, esta instancia funcionaba de manera contrastante con la escena inmediatamente posterior, en la oficina donde se encuentran los tres dibujantes. Aquí, la llegada de la noticia de Barcel sobre la necesidad de despedir a un empleado surge como un factor disruptivo, como una fractura evidente de la tranquilidad de los sujetos haciendo avanzar el enfrentamiento entre los personajes. En el film, en cambio, las primeras imágenes toman distancia del antecedente escénico o, más precisamente, de set televisivo que predomina en el guión firmado por Cossa. Instalando desde su situación de base una evidente desteatralización (Aumont, 2012), la puesta en escena fílmica busca incluir, desde los títulos de crédito, las imágenes de un recorrido a bordo de un auto por el centro de Buenos Aires, el Obelisco y otros edificios-emblema. Acompañando estas tomas de la ciudad aparecen los rostros de los tres protagonistas en primer plano. Separados, caminando, esperando el colectivo o conduciendo, las acciones cotidianas de Gené, Brandoni y Soriano se entremezclan con la de los transeúntes anónimos que los rodean. Cuando la música empieza a decrecer - una melodía tanguera compuesta por el músico Juan Carlo "El Tata” Cedrón que afianza la raíz local del drama- se escucha el primer parlamento. La frase, como una voz over que exterioriza el pensamiento del personaje interpretado por Gené, se interroga: “Todo queda igual. ¿Cómo lo voy a soportar de ahora en adelante?” El espectador lo desconoce, pero estas palabras enuncian el desenlace de la historia. La pregunta de Gené apunta a un dilema ético: ¿Cómo sostener el vínculo con aquellos a los que se consideraba amigos una vez que este se ha visto inevitablemente afectado por la aparición de la mezquindad y los comportamientos deshonestos? La información, aunque opaca, invierte el orden temporal de esta primera escena respecto a todo lo que será mostrado a posteriori. Lo notable de esta elección que trastoca 
radicalmente la organización del relato original se relaciona con su capacidad de pasar desapercibida ante los ojos del público. De manera no subrayada, estas palabras iniciales colocan de cara al público el problema de la condición de rara avis, de la anomalía que representa esta reescritura con relación a la tradición local. Al tratarse de una pieza que nunca fue llevada al escenario, los espectadores se encontraban impedidos de conocer de antemano los pormenores de la trama. Mediante la anticipación del desenlace, Jusid planteaba a la manera de un susurro, el núcleo de la pieza y particularmente lo que a él le había atraído del texto de Cossa al leerlo por primera vez. En un reportaje televisivo, el cineasta decía:

Entre ellos [los personajes] se había gestado una incipiente amistad. Salían juntos, pasaban algún fin de semana... todo era aparente. A mi lo que me interesó de la historia aparte de la denuncia de la racionalización administrativa y ese criterio de dejar en la calle a gente de una manera compulsiva, era cómo, cuando uno mete la uñita en la relación aparente de amistad entre mucha gente, las cosas no son tales, y cómo algunos accidentes en la sociedad o en la vida social de la gente, determinan que el hombre es lobo del hombre. Ese sálvese quién pueda. Ese empujar al otro, al más débil en este caso... Mis amigos jugadores me explicaron que en el tute cabrero siempre hay una alianza entre dos para perjudicar a un tercero. Este es el sentido del título y muy claramente en su momento se lo puso Tito. De alguna manera, lo que yo fui contando en la película fue cómo en cada momento cada uno de ellos busca aliarse con otro para echar al tercero. Y evidentemente lo que puede pasar es que no echen a ninguno. ¿Con qué cara se van a ver el lunes siguiente?7

Potenciando la ambigüedad de la frase, la condición de acción cotidiana, habitual, que asumen los movimientos de los tres protagonistas oscurece aun más el sentido del término todo queda igual. Las palabras parecen aludir en apariencia a la eterna repetición de quien diariamente transita un mismo derrotero para cumplir con sus obligaciones. Sin importar que el espectador conozca a priori el contenido de la trama, el primer parlamento de la película se integra al relato de manera coherente debido a que subraya con efectividad lo repetitivo de los actos mostrados en la pantalla al mismo tiempo que preanuncia el carácter extra cotidiano de la situación vivenciada por los tres oficinistas.

\footnotetext{
${ }^{7}$ Juan José Jusid entrevistado por Roberto Quirno para el programa Argentinos de película, emitido por Canal 7 de Argentina (circa 2005)
} 
El principio es en realidad el final; por ende, ambos quedan homologados. La incertidumbre de Parenti pone de manifiesto el descontento expresado contra lo que quizás pueda aparecer como un dilema existencial: ¿cómo soportar aquello que se reitera incesantemente? Mediante su inclusión en la primera escena, Jusid $-\mathrm{y}$ no Cossa, dado que las palabras no figuraban originalmente en el guión- alude solapadamente a la tradición de lo que la crítica teatral porteña denominó como "teatro del callejón sin salida" (Ordaz, 1966, pp. 10-11).8 Partiendo de esa zona conocida la narración reconfigura en el mismo espacio del relato un giro a los sentidos habituales de estas prácticas proponiendo una significación nueva, respetuosa en iguales proporciones a su capacidad de toma de distancia. Porque justamente esta transformación da en el clavo de aquello a lo que apuntaba el texto -y la poética autoral- de Cossa: su tema no radicaba, como lo leyó la crítica, en la crisis laboral basada en la reducción de puestos de trabajo, sino en las posturas que los antihéroes tomaban y en la incapacidad de la clase media de organizarse más allá de sus propias mezquindades.

\section{Las influencias inversas (del film a la puesta teatral)}

El término empleado aquí para identificar la anomalía representada por la alteración de un orden habitual en el proceso de reescritura - una obra teatral estrenada posteriormente a la película como fue la versión de Tute Cabrero que llevó a escena Raúl Serrano- requiere que se efectúen algunas consideraciones previas relativas a su alcance previendo posibles confusiones sobre las implicancias de esta categoría.

Influencia inversa no refiere a la existencia de un vínculo de subordinación de una disciplina a la otra (en este caso del cine hacia el teatro) mediante el cual deba asumirse como "normal" la supremacía en términos simbólicos de alguno de los campos en cuestión. Esto es aplicable para los distintos momentos de la historia del cine, decididamente más acotada respecto a la cronología teatral,

\footnotetext{
${ }^{8}$ Refiriéndose a las propuestas dramatúrgicas de la nueva camada de autores surgidos en los sesenta Ricardo Halac, Germán Rozenmacher, Rodolfo Walsh y el propio Cossa- Luis Ordaz escribió: "se trata de un simple traslado quietista, sin proyección, que se limita a copiar trozos de una realidad que existe, pero elegidos (los trozos, las situaciones, los personajes) caprichosamente." Más adelante sentenciaba: "Nos encontramos, pues, a pesar del pretendido 'realismo de vanguardia' (...) ante un 'teatro de callejón sin salida'. Bien escrito, habitualmente, con efectos directos en el trazado hábil de lo cotidiano, que atrapan y hallan comprensible resonancia en cierto público, pero con un grave pecado de omisión, que lo parcializa y daña" (Ordaz, 1966, pp. 10-11).
} 
pero particularmente adquiere resonancia en el período analizado en este ensayo. Es incorrecto concebir el diálogo interdisciplinar en función del establecimiento de jerarquías en el arco temporal iniciado en los sesenta y profundizado posteriormente. En esos años los procesos modernizadores ocuparon a las dos disciplinas por igual y de forma paralela.

No constituye una novedad ni un rasgo exclusivamente de esta época que el teatro haya compuesto algunos de sus temas y procedimientos formales a partir de elementos tomados del cine (o bien masificados por este medio). Una concordancia de este tipo podría adjudicarse también, en términos más generales, a la inclusión de fragmentos filmados en las puestas de Erwin Piscator, a las citas cinematográficas tomadas por Bertold Brecht para la construcción de muchas de sus obras - por ejemplo, los filmes de gangsters en La resistible asunción de Arturo Ui (1941) - o, más en profundidad, en el papel superlativo que el montaje ocupa en sus reflexiones sobre el Efecto de distanciamiento; el vínculo también puede hallarse en las conexiones que la configuración física y gestual de Vladimiro y Estragón, los protagonistas de Esperando a Godot, entablan con las máscaras cómicas de Stan Laurel y Oliver Hardy. Los casos singulares podrían extenderse al infinito y a lo ancho de gran parte del entramado histórico del siglo XX (no casualmente llamado el siglo del cine). Sin embargo, lo que sí resulta novedoso es el modo en que se entabla esta relación, que ya no pretende reconocer una estructura ni un orden. Tal como señalaban Michel Delahaye y Jacques Rivette en una entrevista a Roland Barthes publicada en 1962 en Cahiers du Cinéma: "el cine se ha vuelto un objeto de cultura, y todas las artes, todos los pensamientos tienen que referirse a él, como él a ellos" (en Barthes, 2004 [1981], p. 16). En el artículo, los críticos denominan a este fenómeno información recíproca. Más que en otros momentos de la historia del cine es posible pensar desde los sesenta en una paridad posicional de este medio respecto a otros. La información recíproca, entonces, se convierte en una condición de posibilidad para el surgimiento de influencias inversas.

Por su parte, Raúl Serrano, director de la puesta, resulta un caso singular dentro del panorama teatral de esos años. A diferencia de las líneas dominantes de la tradición stanislavskiana en Argentina, vinculadas desde los sesenta a las 
reinterpretaciones del Actor's Studio de Lee Strasberg, su trabajo presenta una variante ortodoxa del sistema Stanislavski, vinculada a los últimos trabajos del creador ruso. Según Karina Mauro, Serrano construye su Método de las Acciones Físicas en el cual "el sujeto se halla presente en la Actuación a través de su acción, exceptuando toda especulación racional o emotiva que lo aísle de las circunstancias de la escena". En función de dicha premisa "la acción es concebida como acontecimiento en el aquí y ahora, y no como elaboración conceptual o narrativa establecida previamente." (Mauro, 2011, pp. 302-303). La transformación respecto del punto de interés en la construcción de los espectáculos provoca que su técnica sea más permeable a emplear estéticas ajenas al realismo, logrando mixturarlas con procedimientos teatralistas que, como en el caso de su labor como director de Tute cabrero, ocupan un lugar protagónico.

En el programa de mano de la versión teatral de la obra, el propio Cossa narraba el periplo que atravesó su creación, admitiendo desde el principio la raíz cinematográfica del texto:

En 1965 un incipiente cineasta me propuso escribir un guión para una película. Se trataba de un proyecto experimental de esos que suelen abordarse con la sola expectativa de hacer algo que a uno le gusta. Tenía en ese entonces un material que tanto yo como el director juzgamos ideal para la experiencia y sobre la base de esa historia escribí el guión del proyectado film. (...)

Casi quince años después, Jorge Álvarez me propuso realizar una experiencia conjunta con un grupo de alumnos egresados de sus cursos de actuación. Les propuse trabajar sobre la historia de "Tute cabrero". (...) A poco de iniciada esta segunda experiencia las primeras imágenes se fueron transformando en acciones teatrales y un día terminaron convirtiéndose en un texto teatral.

Tanto en su debut en cine, como en su aparición teatral, esta historia de los tres dibujantes debe su origen a un mismo impulso: realizar una experiencia con todos los riesgos, pero también con todas las libertades que surgen de este tipo de empresas.

Esta historia que ustedes van a ver atravesó dos veces por esos riesgos y esas libertades. Será por eso que necesitó hacer el trayecto inverso: nacer para el cine y reaparecer luego en el teatro (Las cursivas me pertenecen). 
El calificativo de proyecto experimental asumido reiteradas veces por el autor a lo largo del texto determina una orientación de lectura en la que la distancia respecto a una norma aparece como figura pregnante. En su declaración de intenciones, Cossa formula una genealogía que no solamente reconoce la procedencia cinematográfica sino que asimismo oculta el origen televisivo del guión.9 Como corolario entre el carácter experimental y el reconocimiento parcial de la fuentes, Tute cabrero se configura como una pieza en la que la idea de trayecto inverso resulta determinante. En función de este, es posible ahondar en la influencia ejercida por la película de Jusid en la resolución dramática y espectacular de la versión teatral.

Reconociendo su filiación, la obra establece conexiones con el cine más allá del contenido temático en función del empleo de dos elementos popularizados dentro de este medio: la simultaneidad de las acciones y la inclusión de flashbacks. Al iniciarse la puesta, los seis actores se encuentran presentes en el escenario ocupando distintas porciones de un espacio que, al ser fragmentado mediante objetos, deja entrever al espectador que se trata de ámbitos discontinuos. Desde el planteo escenográfico inicial, los tres tableros de dibujo de los protagonistas dividen las diferentes zonas brindando datos inconfundibles sobre el dilema laboral convertido en tema central de la pieza. En la versión de Raúl Serrano, los muebles de la oficina logran convertirse en virtud de los movimientos de los actores en mesas de comedor que sintetizan la presencia del hogar. Los elementos escenográficos condensan, entonces, una multiplicidad de significaciones que permite reunir lo público y lo íntimo como las dos caras de un mismo problema. Según lo que propone la didascalia inicial, los signos visuales poseen una fuerte mutabilidad que facilita tanto la coexistencia y la ilación tanto de espacios como de tiempos distantes:

La acción transcurre en la oficina de dibujo de la empresa "Alfa” y en cada una de las casas de los tres dibujantes. Pero todo se resuelve en un ámbito único. Están los tableros de los tres dibujantes; una cocina; un living y un dormitorio que pertenecen, indistintamente, a las casas de Sosa, de Carlos y de Serio. En los casos necesarios, los tableros de dibujos se convierten en mesas, Sólo el tablero

\footnotetext{
${ }^{9}$ Las críticas periodísticas al espectáculo tampoco reconocen este antecedente. Se enfatizaba, por lo tanto, el carácter inverso que representaba pasar del cine al teatro. Puede consultarse, por ejemplo, "Del cine a la escena" (1981).
} 
donde trabaja Sosa es inmodificable. Los personajes invaden todos los ámbitos como propios de acuerdo a las necesidades de la acción (...).

La acción real transcurre durante una noche y hasta la mañana del día siguiente. El resto pertenece a los recuerdos de Sosa, a veces, y otras a situaciones que pasaron en a historia de los personajes (Cossa, 1997, p. 203).

De manera análoga a la frase inicial de la película de Jusid en la que irrumpían las cavilaciones de Carlos sobre la relación con los compañeros, las primeras palabras enunciadas en la obra plantean una situación conflictiva desde el punto cero de la acción. El uso de la voz over en la versión cinematográfica, al mismo tiempo que subrayaba la incomunicación entre los personajes, proponía una distancia respecto de los diálogos teatrales a partir de la utilización de un recurso que posibilitaba descentrar la conexión entre la banda visual y la sonora. En la puesta en escena teatral, la materialización del pensamiento es recuperado a partir de la introducción de soliloquios:

SOSA: (Canturrea "El pañuelito blanco" y dibuja) Si el chico dijera "me voy yo", todo sería más fácil. Y así debería ser. iClaro que sí! Le corresponde a él. Es el más joven, entró último y Carlitos y yo nos podemos arreglar solos. (Como si alguien lo contradijera) ¿Cómo que no? ¿Cuánto tiempo estuvimos solos? Y todo andaba bien. Un día vino el chico y la cosa se complicó. Eso es lo que dije, que la cosa se complicó. Nada más que eso. Que Carlitos y yo tendríamos que quedarlos solos (Cossa, 1997, p. 204).

Las primeras palabras de Sosa que inauguran el canal verbal de Tute cabrero aparecen como una exteriorización de la subjetividad. Contrariando una regla tácita de la dramaturgia tradicional que postula que, previo al planteo del conflicto deben quedar presentados los protagonistas principales que lo conducirán, Cossa propone una situación in media res. El motor de la crisis -el anuncio de Barcel sobre la necesidad de despedir a un empleado-, al igual que en el prólogo de la película, pertenece a un momento anterior al presente que sirve como punto de inicio del relato. Mediante esta decisión, el autor asume como un dato significativo que el público probablemente conoce la historia de antemano por haber visto la película (y/o, en menor medida, por haber leído su guión publicado). En consecuencia, la modalidad de apertura elegida opta por eludir las explicaciones introductorias y la caracterización de los personajes. Jugando con las expectativas y el reconocimiento del público, todo en el Tute 
cabrero teatral aparece a la vista desde el primer momento: el conflicto, los actores, los espacios múltiples. Todo salvo un elemento altamente significativo que analizaré más adelante.

Estableciendo una articulación dinámica con el referente cinematográfico, el texto teatral alude al cine valiéndose del empleo de citas como estrategia de reconocimiento de las huellas dejadas por el medio. En un breve ensayo dedicado a recorrer históricamente las relaciones entre el teatro y el cine, Charles Tesson (2012, pp. 44-52) distingue dos instancias en las cuales los filmes han integrado lo escénico en sus composiciones: el mundo del teatro -la aparición de situaciones asociadas a la actividad (los ensayos, la vida de los artistas, todo aquello que sucede "tras bambalinas")- y el momento de teatro, es decir, la inscripción en pantalla de espectáculos concretos incorporados a la diégesis, ya sea por medio de la filmación documental de puestas o bien por el tradicional juego de la representación dentro de la representación. A través de ambas modalidades de inclusión, las películas tendían a subrayar determinadas acciones del relato en función del reconocimiento del grado de problematicidad, de mise-en-abyme, que brota toda vez que un arte refiere explícitamente a otro y lo integra a su propio dispositivo audiovisual. Cossa, consciente del uso histórico de la cita de lo teatral concretada por el cine, efectúa una operación idéntica aunque de manera inversa. Las primeras palabras de Carlos, borracho, aluden de manera oblicua a algunas películas de la era clásica de Hollywood:

CARLOS: Quiero acordarme cómo se llamaba esa película en la que a Edward Robinson le cantaban "porque es un buen compañero... porque es un buen compañero... ¿No te acordás? (...).

LAURA: Te pregunté qué te pasa.

CARLOS: ¿Te parece poco? No me puedo acordar del título de esa película. Todos cantaban "Porque es un buena compañero... porque es un buen compañero...” Y Edward Robinson sonreía. (Observa a Laura, que le lanza una mirada furiosa) Resulta que Edward Robinson era un abogado... No, esa era otra (Cossa, 1997, p. 204).

Carlos intenta rememorar, sin suerte, el nombre de la película de Fritz Lang Perversidad (Scarlett Street, 1945); para ello busca en su memoria queriendo integrar a su mujer en los intersticios de su drama individual contándole la 
trama de otro film, también de Lang: La mujer del cuadro (The Woman in the Windows, 1944) con el mismo reparto protagónico. Cossa se vale de la referencia indirecta - algo que, por otra parte, no figura en la película de Jusid como tampoco aparece en el guión original publicado- para plantear la desazón de un personaje que intenta recobrar infructuosamente un tiempo perdido en el que unos compañeros de trabajo homenajeaban en una cena de camaradería a uno de ellos. La cita cinéfila, puesta a la manera de un guiño indirecto para aquellos asistentes a las funciones que tenían conocimiento de los filmes de Lang y de la confusión entre ambas películas queda resignificada en función del propio dilema que experimenta Carlos. El protagonista de Tute cabrero es un hombre mediocre que, al igual que aquellos interpretados por Edward Robinson en el díptico languiano, vive una vida apacible hasta que una situación sorpresiva impone un viraje que lo obliga a sumergirse inexorablemente en la crisis.

El guión original recurría a la escena del brindis situándolo como instancia que rubricaba la presentación de los personajes. Mediante una estrategia de economía narrativa (de orden clásico), esta instancia posibilitaba a su vez esbozar la prehistoria y la cordial camaradería no exenta de afecto que impregnaba el vínculo entre los compañeros de trabajo. En el film de Jusid estas acciones aparecían promediando el relato, durante el paseo de Sergio y Gladys en el que este relata su delación a Sosa. El recuerdo, activado probablemente por Gladys - unos travellings de acercamiento y distancia que reencuadran su rostro en primer plano sirven de marco para la introducción del flashbacksmuestra los festejos. La música melancólica se transforma en un jazz trepidante mientras la puesta en escena abandona la Costanera sur por el interior de la casa de uno de los oficinistas. En tanto los movimientos de la cámara y la sustitución de la música subrayan ante el espectador de manera explícita la presencia de un tiempo diferido, la forma en que el pasado toma cuerpo plantea una complejidad fundada en la discordancia entre la banda visual y la sonora. La disociación entre las imágenes y las palabras de Sergio hacen coexistir dos momentos diferentes bajo un denominador común: visualmente vemos a los tres hombres, a Laura y a Gladys brindando, bailando, abrazándose y en simultáneo, escuchamos una conversación anterior, en la que Sergio le habla a su pareja sobre sus colegas y planean la fiesta que aparece en pantalla. "Me 
gustaría que los conocieras. Son tipos macanudos. El viejo es fenómeno... yo siempre lo cargo. Pero es un buen tipo. ¿Por qué no los invitamos a casa? De paso festejamos el fin de año..." enuncia la voz over de Sergio.

En La imagen-tiempo, Deleuze proponía que, para que los flashbacks pierdan su carácter convencional y su determinismo sensoriomotor, es decir, para quedar articulados dentro de un relato no ya clásico sino plenamente moderno, estos deberían recibir su justificación diegética a través de una instancia externa. "Las bifurcaciones del tiempo dan una necesidad al flash-back y confieren a las imágenes-recuerdo una autenticidad" (Deleuze, 2005, p. 75). La conjugación de momentos distantes que pautan el recuerdo de Gladys, plantea esta bifurcación de una temporalidad que no es, como en el cine clásico, el pasado actualizado como presente sino algo más ambiguo, producto de los circuitos sinuosos de la memoria del personaje.

Coexistencia de tiempos y espacios distantes. Ambos elementos aparecen conjugados en la traslación cinematográfica de esta escena fundacional expresada por el guión a la manera de un prólogo. Si, según entiende Deleuze, la importancia de la inclusión de flashbacks en los relatos se asocia a que se trata de historias que solamente pueden ser contadas en pasado (Deleuze, 2005, p. 75), el tratamiento en la película asume esta premisa demostrando que, frente a un estado de crisis instalado desde la frase inicial, la felicidad de los sujetos del drama forma parte de un universo perdido, solo recuperable parcialmente a través de la primacía de una subjetividad que muestra la inestabilidad de los recuerdos.

Debido a este estado de cosas, en la puesta teatral Carlos está impedido de recordar el nombre de las películas de Fritz Lang; obras cuyos periplos dramáticos apelan al pasaje tradicional del cosmos - la canción "Porque es un buen compañero" que le cantan a E. Robinson - al caos: el hundimiento en la tragedia por haber optado salir de su tranquilidad. Desde la fluctuación moderna entre diversas capas temporales partirá Cossa para reescribir su propia obra que, mientras es montada en un escenario, se encarga re recobrar insistentemente, casi como un síntoma, su procedencia cinematográfica.

No obstante a haber ensayado ya en una pieza temprana - La pata de la sota (1967) - esta táctica de fractura de la linealidad del relato, en su reescritura de 
Tute cabrero, el autor agregó a este procedimiento en el que el tiempo se traslada libremente del pasado al presente, la coexistencia de acciones correspondientes a momentos diversos. Como en el tratamiento del flashback del brindis propuesto en la película, Cossa recupera esta estrategia de mezcla en la que las temporalidades se encabalgan y confluyen propiciando un interesante juego teatral que, a todas luces, remite a una tradición fílmica. Volviendo al modo en que el autor (re)construye su propio relato en la escena del brindis: esta se inicia en la oficina; Sergio entrega a Carlos y a Sosa unas artesanías de regalo hechas por Gladys. Es un simple gesto de reconocimiento por el primer año de Sergio en la empresa; Carlos extiende el cenicero que le regalaron a Laura, que, en el mismo escenario, ocupa un espacio ficcional distinto:

CARLOS: Yo, el cenicero me lo llevo a casa. Me viene muy bien (Se lo tiende a Laura.)

LAURA: Es hermoso. ¿Lo hizo la chica? Tendríamos que invitarlos a cenar una noche.

CARLOS: Buena idea. (A Sergio.) ¿El sábado pueden? Así, de paso, la conocemos a Gladys (Cossa, 1997, p. 208).

El juego establecido a través del pase de manos del cenicero de Carlos a Laura conecta en una ilusoria inmediatez dos espacios y tiempos diferentes. Además, esto funciona como excusa argumental para proponer el festejo que prosigue a la escena de los regalos:

(Es otro momento del recuerdo. Ríen. Ya están en la fiesta. Carlos sirve los vasos). SOSA: (Dibuja. Fija la vista) ¿Qué número es éste?

MATILDE: Un cuatro.

SOSA: Los hacen cada vez más chicos.

MATILDE: ¿Vas a venir, no, Luis?

SOSA: Tengo que terminar el plano.

MATILDE: Siempre que salís de casa, pienso: hoy no vuelve (...).

SOSA: Son las once. Me voy a tener que ir.

LAURA: Es temprano, todavía.

SOSA: Mi hermana está sola. 
CARLOS: Tómese la última.

SOSA: Tengo que terminar el plano. (Cossa, 1997, p. 209).

El presente de la acción, en el que Sosa dibuja el plano, se mezcla con su recuerdo de la fiesta. A su vez, ambos momentos se entrecruzan a partir de la inclusión de Matilde, la hermana de Sosa, que no participa efectivamente de ninguno de estos lugares - la oficina y la casa de Carlos-. En la puesta, los personajes se unen y se separan, dialogan e intervienen en el espacio ajeno generando una confusión entre los distintos tiempos del relato. Al encabalgamiento producido en el cine por el contraste entre la banda visual y la sonora, la puesta de Serrano responde con la mutabilidad de los signos escénicos como estrategia para alcanzar iguales objetivos. La urgencia de Sosa por volver a su casa se mezcla con su desesperación por terminar el plano antes del día en que se decidirá cuál de los dibujantes deberá ser despedido. Reescribiendo su propio guión a partir del precedente de la película de Jusid, Cossa resuelve que aquello que había propuesto inicialmente como un muestrario de la felicidad, como la ilusión del compañerismo que reinaba en el ambiente, está en este caso ya teñido por el conflicto.

En función de las citas indirectas a las películas de Fritz Lang, de la simultaneidad espacial y del constante uso de flashbacks contaminados por el presente, la propuesta teatral reconoce sus influencias inversas con respecto a la película que la precedió. Ahora bien, la reconfiguración que recibe el tratamiento de una cuestión particular trasciende las formas cinematográficas y concede una relación abierta de la pieza de Cossa con las formas teatrales del momento.

Tanto en el guión original como en la película, la figura de Barcel, el gerente de "Alfa" que impone el desencadenamiento del conflicto entre los oficinistas, está tratada de manera realista: su aparición obtiene cuerpo y voz a través de una carnadura específica (el actor Alejandro Marcial). En la reescritura de Cossa, en cambio, el personaje nunca aparece efectivamente en escena; su participación en el relato se genera por medio de un altavoz. Esta presencia intermedia, carente de un cuerpo específico, recuerda a los “personajes inefables” del teatro absurdista. Como Godot o la cantante calva, Barcel no posee una fisonomía específica. En este punto, la dramaturgia de Cossa se reafirma en la teatralidad y 
establece una distancia con la referencialidad realista aplicada por el cine. Barcel, al carecer de un cuerpo predeterminado, posee todas las encarnaciones posibles, por lo menos aquellas adjudicables por el espectador a sujetos pertenecientes a esa clase, la de un emisario de la burguesía capacitado para provocar un enfrentamiento entre los empleado por ver quién conserva y defiende de manera individualista sus fuentes de trabajo. Mediante este simple cambio en el tratamiento de un personaje, Cossa reconfigura su propia escritura, llevándola del realismo a la exposición de una alegoría manifiesta.

\section{Conclusión}

Reflexionando sobre las relaciones artísticas de la centuria pasada, Óscar Cornago Bernal describe un estado de situación en el que las prácticas tendieron a mezclarse inexorablemente, al punto de tornar irreconocibles sus bordes y probablemente también sus especificidades:

en el siglo XX cada arte ha tratado de ser otro, la poesía quiere hacerse realidad escénica y el teatro espacio para la música; la palabra ser sonido y el sonido grafía; la danza sueña con ser drama y el drama con devenir narrativa; la pintura se pone en escena por medio de las instalaciones y el cine quiere ser pintura en movimiento (Cornago Bernal, 2005, p. 11).

A partir del análisis de un caso anómalo de trasvase de un medio a otro (del guión televisivo al film) y de su posterior reescritura teatral (que en cierto modo implicó una reelaboración sobre las bases aportadas por la versión cinematográfica) se buscó mostrar lo sinuosas que resultaron las relaciones entre dos campos artísticos que, en el panorama argentino de los años sesenta, se hallaban en franco proceso de transformación. Sobre todo a partir de la segunda mitad de aquella década este vínculo, merced al corrimiento de los límites disciplinares, permitió la aparición de formas innovadoras que vendrían a impugnar un estado asumido casi como natural. Ya no se trató de un medio o un arte de masas (el cine) nutriéndose de otro legitimado y con una amplia trayectoria (el teatro) sino de un nuevo mecanismo que radicalizó la lógica de consagración horizontal imperante en toda esta etapa. Como resultado de este nuevo reparto de las barajas surgieron prácticas de reescritura que dinamitaron algunas certezas a tal punto de tornar indiscernible (o por lo menos poco 
importante) el reconocimiento de los antecedentes o la atribución de "paternidades". Apareciendo bajo la forma de un síntoma específico de la fase denominada "de intermedialidad profunda" se hicieron visibles en esta etapa unas estrategias de traslación de textos que tendieron a subvertir la tradicional ordenación entre obra fuente y obra destino que hasta el momento había predominado en el panorama de los intercambios transpositivos entre el teatro y el cine.

Por otra parte, al complementar el enfoque comparativo (inmanente) con otros datos provenientes del contexto de producción, el estudio de las distintas versiones de Tute cabrero habilitó el trazado de puntos de contacto con otras disciplinas contemporáneas que también enriquecieron las interpretaciones sobre la(s) obra(s). La comparación efectuada con el tratamiento de los problemas de lo íntimo y lo público en la película de Jusid con relación a $E l$ baño de Roberto Plate dejan entrever la existencia de conexiones más allá de aquellas que suponen las operaciones de trasvase de un texto. De esta manera, ampliar la mirada a cierto ethos epocal ayudó a echar luz sobre ciertos problemas formales y temáticos articulados en la pieza.

Como pudo verse en el examen de Tute cabrero, si el teatro (y la televisión) pudieron aportar varias cuestiones al cine, quedó demostrado también el modo en que esta última disciplina también contribuyó a dotar a la escena de diversos aspectos. La condición de posibilidad que tornó efectiva estos cruces se asoció con la certeza, por parte de los artistas, de estar situados ante una paridad posicional. En una instancia en cierto modo temprana como 1981, la versión de Raúl Serrano puso de manifiesto un estado de situación que con el correr de las décadas iría profundizándose. En los últimos años el hecho de que el teatro retome sus temas de filmes concretos resulta un lugar cada vez más transitado. Las versiones escénicas de varias películas de Ingmar Bergman, de Fernando Fernán Gómez, Vicente Aranda, ${ }^{10}$ e incluso la puesta teatral de la primera película del Dogma '95, La celebración (Thomas Vinteberg, 1998), ejemplifican la actualidad de una modalidad de intercambio que ha ido ganando sistematicidad.

\footnotetext{
${ }^{10}$ El viaje a ninguna parte y Amantes, de Fernán Gómez y Aranda, respectivamente, fueron llevadas a escena en Madrid en la temporada 2014.
} 
$\mathrm{Si}$, como indica la propiedad conmutativa "el orden de los factores no altera el producto" estos textos (y en general todos aquellos situados en unos momentos de radicalización de las prácticas artísticas) indicaron lo contrario. Más bien argumentaron que el orden, los límites, las fronteras, se constituían en obstáculos a ser derribados.

\section{Referencias bibliográficas}

Aumont, J. (2012). El cine y la puesta en escena. Buenos Aires: Colihue.

Barthes, R. (2004). El grano de la voz. Entrevistas 1962-198o. Buenos Aires: Siglo XXI.

Berman, M. (2004 [1985]). Brindis por la modernidad. En Nicolás Casullo (Comp.) El debate modernidad posmodernidad. Buenos Aires: Retórica, pp. 87-105.

Carlón, M. (2006). De lo cinematográfico a lo televisivo. Metatelevisión, lenguaje y temporalidad. Buenos Aires: La Crujía.

Cattrysse, P. (1992). Pour une théorie de l'adaptation filmique. Le film noir américain. Berna: Peter Lang.

Cornago Bernal, O. (2005). Resistir en la era de los medios. Estrategias performativas en literatura, teatro, cine y televisión. Madrid-Frankfurt am Main: Iberoamericana/Vervuert.

Deleuze, G. (2005). La imagen-tiempo. Estudios sobre cine 2. Barcelona: Paidós.

Cossa, R. (1997). Teatro 1. Nuestro fin de semana, Los días de Julián Bisbal, La ñata contra el libro, La pata de la sota, Tute cabrero. Buenos Aires: De la flor.

Del cine a la escena (1981). En Clarin, Suplemento Espectáculos. Buenos Aires: 23 de abril, pp. 4-5.

Genette, G. (1989). Palimpsestos. La literatura de segundo grado. Madrid: Taurus.

Jordan, P. (2007). Roberto Arlt y los años sesenta: crítica y recepción. En Fragmentos, Revista de Lingua e Literatura Estrangeiras da Universidade Federal de Santa Catarina Num. 32, pp. 23-32 https://periodicos.ufsc.br/index.php/fragmentos/article/view/1706/788 3

Longoni, A. y Mestman, M. (2008). Del Di Tella a Tucumán arde. Vanguardia artística y política en el 68 argentino. Buenos Aires: EUDEBA.

Masotta, O. (2004). Revolución en el arte. Pop art, Happenings y arte de los medios en la década del sesenta. Barcelona: Edhasa.

Mauro, K. (2011). La Técnica de Actuación en Buenos Aires. Elementos para un Modelo de Análisis de la Actuación Teatral a partir del caso porteño. 
Tesis doctoral inédita, Universidad de Buenos Aires. (Versión digital facilitada por la autora).

Ordaz, L. (1966) Panorama del teatro argentino en los últimos años. Talía, Año $\mathrm{V}(30)$, pp 10-11.

Peña, F. M. (comp.) (2003). 60/9o Generaciones. Cine argentino independiente. Buenos Aires: Ed. Malba. Colección Constantini.

Pérez Bowie, J. A. (2004). Las adaptaciones cinematográficas a la luz de algunas aportaciones teóricas recientes. Revista Signa, num. 13, pp. 277-300.

Pérez Bowie, J. A. (2010). Sobre reescritura y nociones conexas. Un estado de la cuestión, en José Antonio Pérez Bowie (ed.) Reescrituras fílmicas. Nuevos territorios de la adaptación. Salamanca: Universidad de Salamanca, pp. 21-43.

Pinta, Ma. F. (2013). Teatro expandido en el Di Tella. La escena experimental argentina en los años 6o. Buenos Aires: Biblos.

Terán, O. (1991). Nuestros años sesenta. La formación de la nueva izquierda intelectual argentina. 1956-1966. Buenos Aires: Puntosur.

Tute Cabrero. iAl diablo con los esquemas! (1968). En Siete Días, Año 1 (42) 27 de febrero, pp. 53-57.

Tesson, Ch. (2012). Cine y teatro. Barcelona: Paidós.

Vindel, J. (2014). Por un arte semiológico: “deshabituación” y "discontinuidad" en el arte argentino de los años sesenta. Revista Arte, Individuo y Sociedad, 26 http://dx.doi.org/10.5209/rev_ARIS.2014.v26.n3.43406

Weiss, P. y Jusid, J. J. (1968). Marat/Sade y Tute cabrero. Buenos Aires: Pedro Sirera. 